\title{
Epigallocatechin-3-gallate induces oxidative phosphorylation by activating cytochrome c oxidase in human cultured neurons and astrocytes
}

\author{
Gloria Castellano-González ${ }^{1}$, Nicolas Pichaud ${ }^{2}$, J. William O. Ballard ${ }^{3}$, Alban \\ Bessede ${ }^{4}$, Helder Marcal ${ }^{5}$ and Gilles J. Guillemin ${ }^{1}$ \\ 1 MND and Neurodegenerative Diseases Research Group, Australian School of Advanced Medicine (ASAM), Macquarie \\ University, Sydney, Australia \\ 2 Department of Biological and Environmental Sciences, University of Gothenburg, Göteborg, Sweden \\ ${ }^{3}$ School of Biotechnology and Biomolecular Sciences, The University of New South Wales, Sydney, Australia \\ ${ }^{4}$ Immusmol Pty Ltd, Pessac, France \\ ${ }^{5}$ Topical Therapeutics Research Group, School of Medical Sciences, The University of New South Wales, Sydney, Australia \\ Correspondence to: Gilles J. Guillemin, email: gilles.guillemin@mq.edu.au \\ Keywords: epigallocatechin-3-gallate, ATP, neurodegeneration, cytochrome c oxidase, mitochondria, Gerotarget \\ Received: October 27, 2015 \\ Accepted: December 24, 2015 \\ Published: January 09, 2016
}

\section{ABSTRACT}

Mitochondrial dysfunction and resulting energy impairment have been identified as features of many neurodegenerative diseases. Whether this energy impairment is the cause of the disease or the consequence of preceding impairment(s) is still under discussion, however a recovery of cellular bioenergetics would plausibly prevent or improve the pathology. In this study, we screened different natural molecules for their ability to increase intracellular adenine triphosphate purine (ATP). Among them, epigallocatechin-3-gallate (EGCG), a polyphenol from green tea, presented the most striking results. We found that it increases ATP production in both human cultured astrocytes and neurons with different kinetic parameters and without toxicity.

Specifically, we showed that oxidative phosphorylation in human cultured astrocytes and neurons increased at the level of the routine respiration on the cells pre-treated with the natural molecule. Furthermore, EGCG-induced ATP production was only blocked by sodium azide $\left(\mathrm{NaN}_{3}\right)$ and oligomycin, inhibitors of cytochrome $\mathrm{c}$ oxidase ( $\mathrm{CCO}$; complex IV) and ATP synthase (complex V) respectively. These findings suggest that the EGCG modulates CcO activity, as confirmed by its enzymatic activity. $\mathrm{CcO}$ is known to be regulated differently in neurons and astrocytes. Accordingly, EGCG treatment is acting differently on the kinetic parameters of the two cell types. To our knowledge, this is the first study showing that EGCG promotes CcO activity in human cultured neurons and astrocytes. Considering that $\mathrm{CcO}$ dysfunction has been reported in patients having neurodegenerative diseases such as Alzheimer's disease (AD), we therefore suggest that EGCG could restore mitochondrial function and prevent subsequent loss of synaptic function.

\section{INTRODUCTION}

EGCG is the main polyphenol component of green tea, representing more than $10 \%$ extract in dry weight. This naturally occurring molecule is a flavonoid that belongs to the catechin subgroup. The strongest bioactivity of flavonoids is anti-oxidant which is potentiated by the catechol structure. This functional group can chemically scavenge reactive oxygen species (ROS) at relatively low concentrations [1-3] but has pro-oxidative/pro-apoptotic properties at higher concentrations [4]. Moreover, it can modulate protein functions through interactions within their hydroxyl group and the amino and carbonyl groups in proteins [5]. These properties have conferred multiple physiological and therapeutic benefits to EGCG. For example, it has been used in cancer therapy for its 
apoptotic and anti-proliferative properties and its activity on immune response [6-10]. EGCG has also been shown to be beneficial in autoimmune diabetes due to its antiinflammatory activity in different cell types [11]. Finally, it has important protective effects in neurodegenerative diseases involving different molecular mechanisms and signaling pathways (Reviewed by Mandel [12]).

Although many studies attribute the neuroprotective role of EGCG to its properties as a radical scavenger, other pharmacological properties may further contribute to its therapeutic benefits. Neurodegenerative diseases are usually accompanied by fuel restrictions in neurons and mitochondrial impairment. EGCG has been previously shown to target energy metabolism in several cell types, mainly as an agonist of the main cellular energy sensor, adenosine monophosphate- activated protein kinase (AMPK) $[13,14]$. Studies in mice demonstrated that EGCG can cross the blood barrier and reach the brain $[15,16]$ and it has been shown to accumulate in neuronal mitochondria [2]. Of interest, it has also been shown to restore mitochondrial membrane potential, mitochondrial function as well as ATP synthesis in AD mice model [1, 17].

Lower ATP production and increased formation of ROS in mitochondria are commonly observed alongside $\mathrm{CcO}$ impairment [18], which was shown to occur in AD pathology and other neurodegenerative diseases. $\mathrm{CcO}$ is the terminal oxidase of the mitochondrial electron transport system (ETS) and catalyzes the final step of the electron transfer from reduced cytochrome $\mathrm{c}$ to oxygen. It is also one of the proton pumps that generate the proton gradient across the inner mitochondrial membrane to power ATP synthesis. Additionally, it should be considered that $\mathrm{CcO}$ regulation, assembly and structure is complex and tissue specific [19].

Our results showed that EGCG induces $\mathrm{CcO}$ activity in human cultured neurons and astrocytes. It suggests that in addition to its antioxidant properties EGCG can induce mitochondrial respiration by activating $\mathrm{CcO}$ in human cultured neurons, increasing ATP production without altering redox balance. Therefore using EGCG because of its polypharmacological activities, its bioavailability properties and its restoring effect on mitochondrial function makes it a promising candidate for treating several neurodegenerative diseases with mitochondrial impairment as a common feature.

\section{RESULTS}

\section{EGCG induces ATP production in human cultured neurons and astrocytes with different kinetics and dose-response patterns}

After EGCG was selected for its capacity to increase ATP production in human cultured neurons (see Supplementary Figure 1), we investigated the mechanism of action of EGCG-induced ATP production by performing dose-response and kinetic studies in the two main cell types present in the brain: neurons and astrocytes.

Both neurons and astrocytes showed a two-fold increase in ATP production after $2 \mathrm{~h}$ treatment with 10 $\mu \mathrm{M}$ EGCG. In neurons, the ATP production is maintained and increased over $72 \mathrm{~h}$ (Figure 1A) whereas in astrocytes the ATP is restored to basal levels after 6h (Figure 1B). Neurons and astrocytes were treated with different dose of EGCG ( 1 to $100 \mu \mathrm{M}$ ) for $2 \mathrm{~h}$ in astrocytes and $24 \mathrm{~h}$ in neurons. Increasing concentrations of EGCG (up to $60 \mu \mathrm{M}$ ) correlate with increasing production of ATP in neurons (Figure 1C). In astrocytes however, ATP production was maximal at $1-10 \mu \mathrm{M}$, and dropped at higher concentrations (Figure 1D). Cytotoxicity studies were done in parallel to verify that the treatments used were not causing cell death and that the increase of ATP observed was not due to induction of apoptotic pathways. Lactate dehydrogenase (LDH) was measured in the supernatant of each condition, showing no cytotoxicity over $72 \mathrm{~h}$ in neurons and astrocytes treated with $10 \mu \mathrm{M}$ of EGCG (Figure 1E). However, cell death was induced in neurons and astrocytes when treated for $24 \mathrm{~h}$ with more than $30 \mu \mathrm{M}$ and $10 \mu \mathrm{M}$ of EGCG, respectively (Figure $1 F)$. These results correlate with the decrease in ATP production observed in neurons (Figure 1C) at higher concentrations than $60 \mu \mathrm{M}$.

\section{EGCG increases mitochondrial membrane potential in both astrocytes and neurons}

Mitochondrial membrane potential $\left(\Delta \psi_{\mathrm{m}}\right)$ relates to cells' capacity to generate ATP by oxidative phosphorylation [20]. Due to the increase in ATP production observed after $2 \mathrm{~h}$ treatment (Figure $1 \mathrm{~A}, 1 \mathrm{~B}$ ), we hypothesized that EGCG may be acting directly in one of the two main sources of ATP production in the cell: oxidative phosphorylation or glycolysis. Taking into account that the main source of ATP in neurons is mitochondrial oxidative phosphorylation [21] and that the effect of EGCG on ATP production is significantly higher in neurons than in astrocytes (Figure 1A, 1C), we therefore looked at the effect of EGCG on mitochondrial function. We examined changes on the $\Delta \psi_{\mathrm{m}}$ with two different probes: R123 and CMXRos. Treatment with EGCG 
A
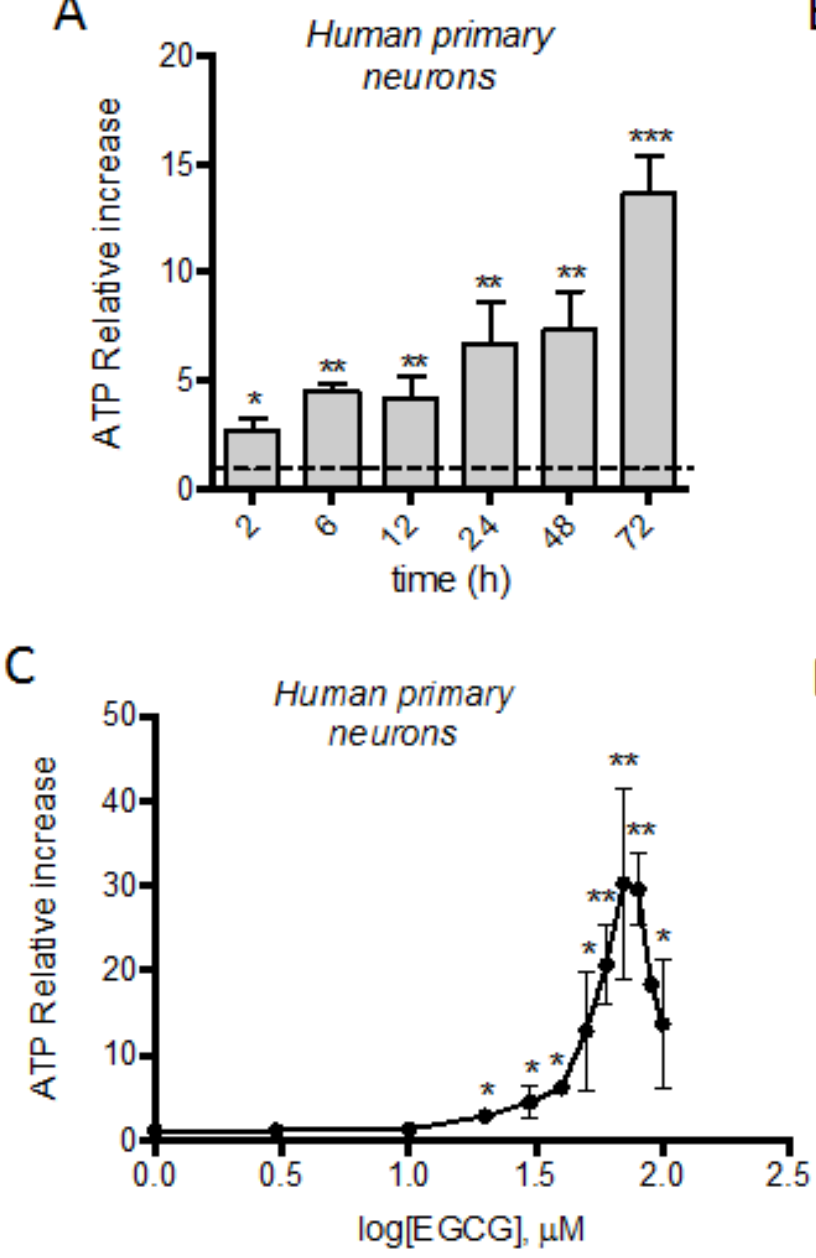

$E$

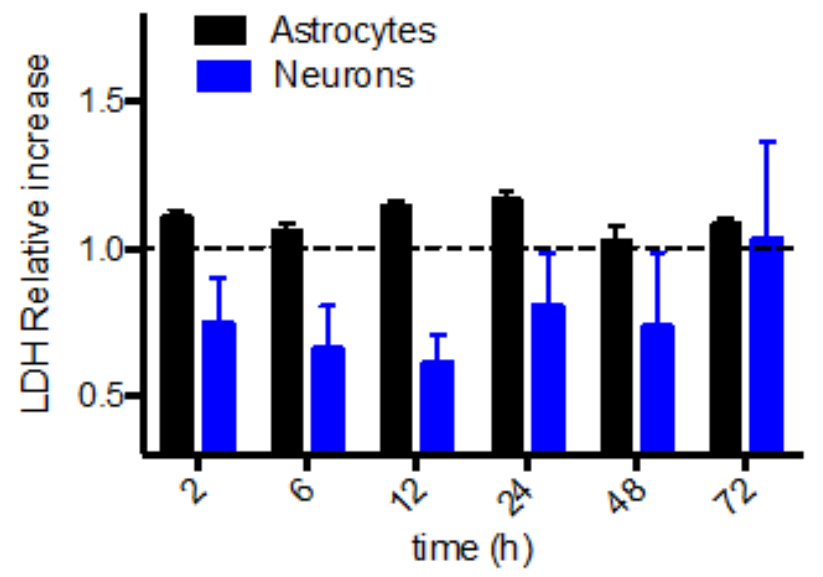

B
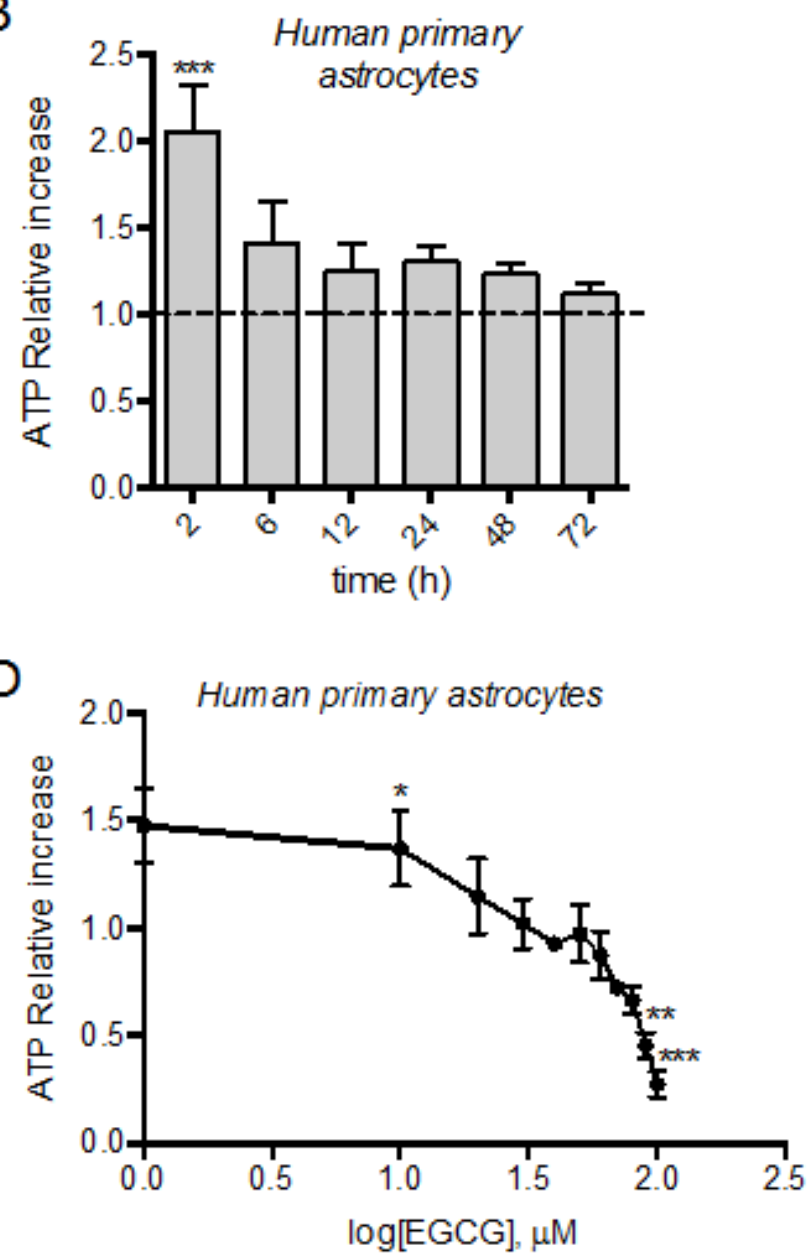

$\mathrm{F}$

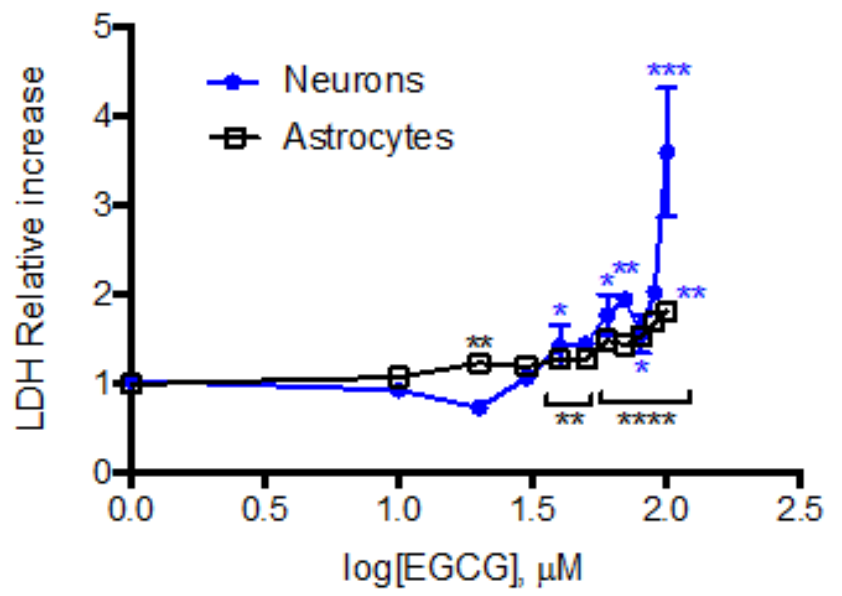

Figure 1: ATP modulation in neurons' and astrocytes' by EGCG treatment. ATP production of neurons and astrocytes after treatment with $10 \mu \mathrm{M}$ EGCG at different time points A., B. and with increasing concentrations $(1-100 \mu \mathrm{M})$ for $24 \mathrm{~h} \mathbf{C}$. or $2 \mathrm{~h} \mathbf{D}$. was assessed by luminescent intensity. Data (means \pm s.e.m. of three or six experiments) are presented as normalized mean intensity in sample relative to normalized mean intensity in untreated sample for each time point. ${ }^{*} p \leq 0.05,{ }^{* *} p \leq 0.01,{ }^{* * *} p \leq 0.005$ (treatment versus none; Student's $t$-test). Cell death of neurons and astrocytes after treatment with $10 \mu \mathrm{M} \mathrm{EGCG}$ at different time points $\mathbf{E}$. and with increasing concentrations $(1-100 \mu \mathrm{M})$ for $24 \mathrm{~h}$ neurons or $2 \mathrm{~h}$ astrocytes $\mathbf{F}$. assessed by LDH activity in cell supernatant. Data (means \pm s.e.m. of three experiments) are presented as normalized mean activity in sample relative to normalized mean activity in untreated sample for each time point. $* p \leq 0.05$, ${ }^{* *} p \leq 0.01,{ }^{* * *} p \leq 0.005, * * * * p \leq 0.001$ (treatment versus none; Student's $t$-test). 
showed an increase in $\Delta \psi_{\mathrm{m}}$ by R123 fluorescence in both cell types, reaching its maximum after 10 minutes in astrocytes and $1 \mathrm{~h}$ in neurons (Figure 2A). Study of relative changes of $\Delta \psi_{\mathrm{m}}$ was also performed using CMXRos [22] in human cultured neurons, as the increase of $\Delta \psi_{\mathrm{m}}$ showed by R123 was only maintained over the time in neurons but not in astrocytes. We observed an increase on the relative fluorescence intensity of CMXRos within the neuronal mitochondria after 10 minutes treatment with EGCG (Figure 2B). Thus, the induction of R123 and CMXRos fluorescence indicates that EGCG increases $\Delta \psi_{\mathrm{m}}$. Moreover, it suggests that EGCG effect on ATP production could be mediated by induction of the ETS.

\section{EGCG increases mitochondrial respiration in intact neurons and astrocytes but does not induce mitochondrial biogenesis}

Mitochondria produce ATP via the electrochemical proton motive force $(\Delta p)$, which is due to the transfer of electrons through the complexes of the ETS and provides the energy to drive the protons against their concentration gradient across the inner mitochondrial membrane [20]. $\Delta \mathrm{p}$ in the mitochondria is dependent of $\Delta \psi_{\mathrm{m}}$ and the mitochondrial $\mathrm{pH}$ gradient $(\Delta \mathrm{pH})$ and can be represented at $37^{\circ} \mathrm{C}$ by the equation: $\Delta \mathrm{p}(\mathrm{mV})=\Delta \psi_{\mathrm{m}}-60 \Delta \mathrm{pH}$. It should be taken into account that $\Delta \psi_{\mathrm{m}}$ does not necessarily follow the proton gradient $\left(\Delta \mathrm{pH}_{\mathrm{m}}\right)$, which is directly related to ATP production. During cellular stress, $\Delta \psi_{\mathrm{m}}$ could be altered by deregulation of intracellular ionic charges (eg. $\mathrm{Ca}^{2+}$ or $\mathrm{K}^{+}$), independently of ETS induction [23]. In order to assure that the changes observed in $\Delta \psi_{\mathrm{m}}$ are mediated
A

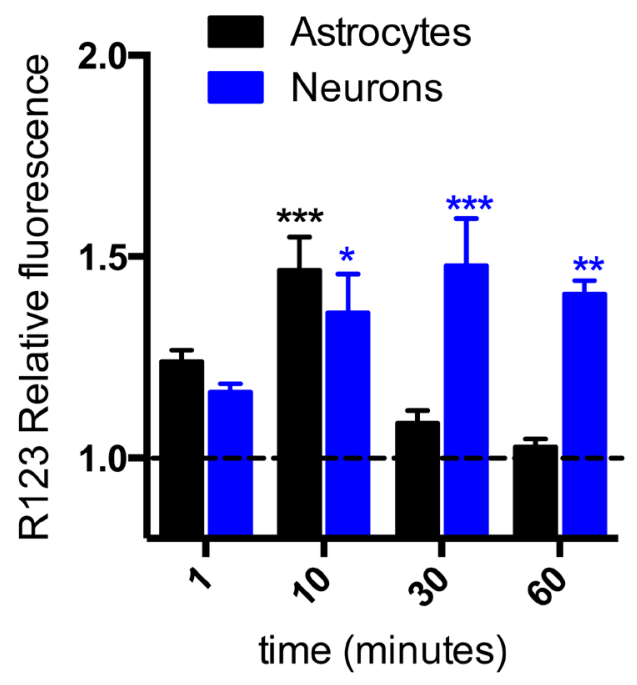

B
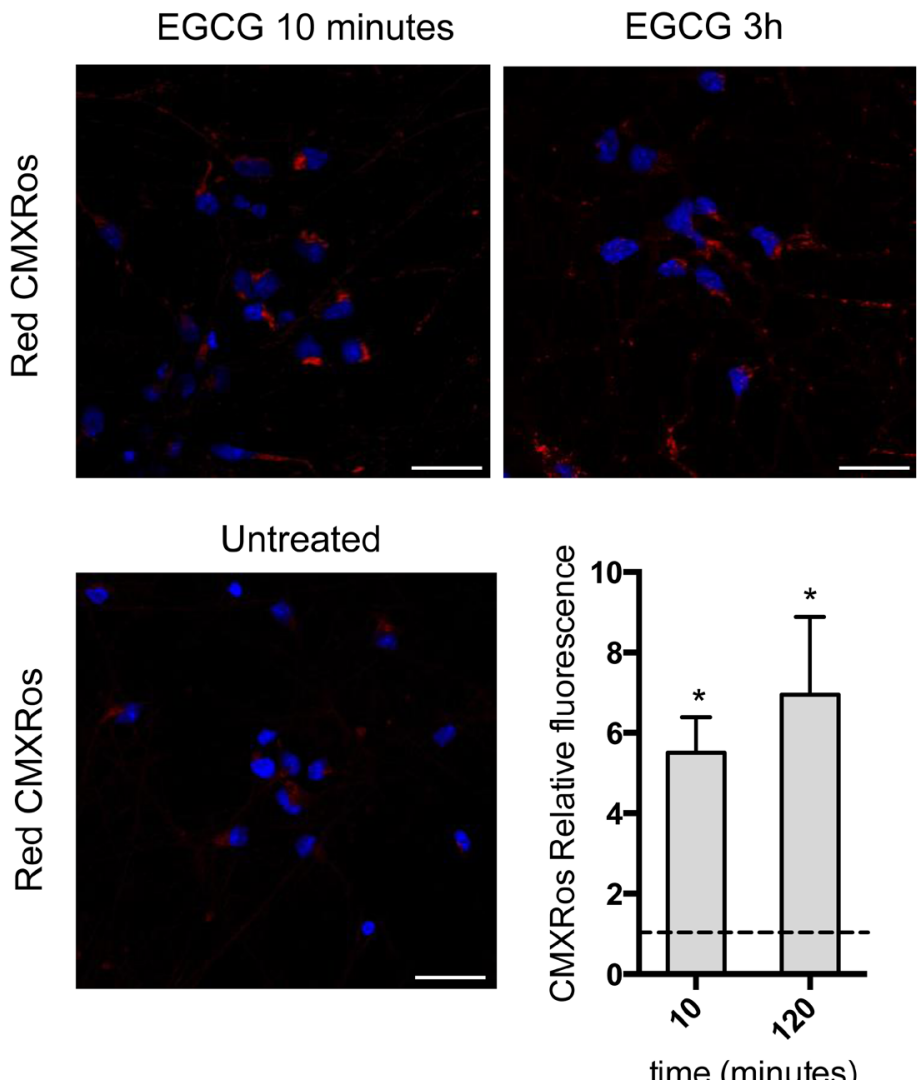

Figure 2: EGCG increases mitochondrial membrane potential. A. Mitochondrial membrane potential of astrocytes and neurons assessed by R123 fluorescence intensity measured at different time points after $10 \mu \mathrm{M}$ of EGCG treatment. Data (means \pm s.e.m. from three experiments) are presented as mean fluorescence in sample relative to mean fluorescence in untreated sample for each time point. ${ }^{* * *} p \leq 0.001, * * p \leq 0.005,{ }^{*} p \leq 0.01$ (treatment versus none; Student's $t$-test). B. Mitochondrial membrane potential of neurons assessed by MitoTracker CMXRos fluorescence intensity after treatment with $10 \mu \mathrm{M}$ of EGCG. Images represent single fields from $>10$ fields per sample in two independent experiments. Scale bar: $25 \mu \mathrm{m}$. Data (means \pm s.e.m. of two experiments) are presented as normalized mean fluorescence in sample relative to normalized mean fluorescence in untreated sample for each time point. ${ }^{*} p \leq 0.01$ (treatment versus none; Student's $t$-test). 
by ETS induction, we monitored cell oxygen consumption using high-resolution respirometry.

Considering that EGCG increases $\Delta \psi_{\mathrm{m}}$ within 10 minutes, the $\mathrm{O}_{2}$ rate was monitored before and after EGCG addition. We found that addition of $10 \mu \mathrm{M}$ EGCG immediately increased routine $\mathrm{O}_{2}$ consumption (R) in neurons (Figure 3B) and astrocytes (Figure 3A). No significant differences were observed in proton leak or
ETS capacity. Cellular routine respiration is supported by exogenous substrates in the culture medium. Only physiological energy demand, energy turnover and the degree of coupling (intrinsic uncoupling and pathological dyscoupling) control the levels of respiration and phosphorylation in the physiological $\mathrm{R}$ of intact cells $[24,25]$. Knowing that EGCG does not increase energy demand and that there are no changes on intrinsic
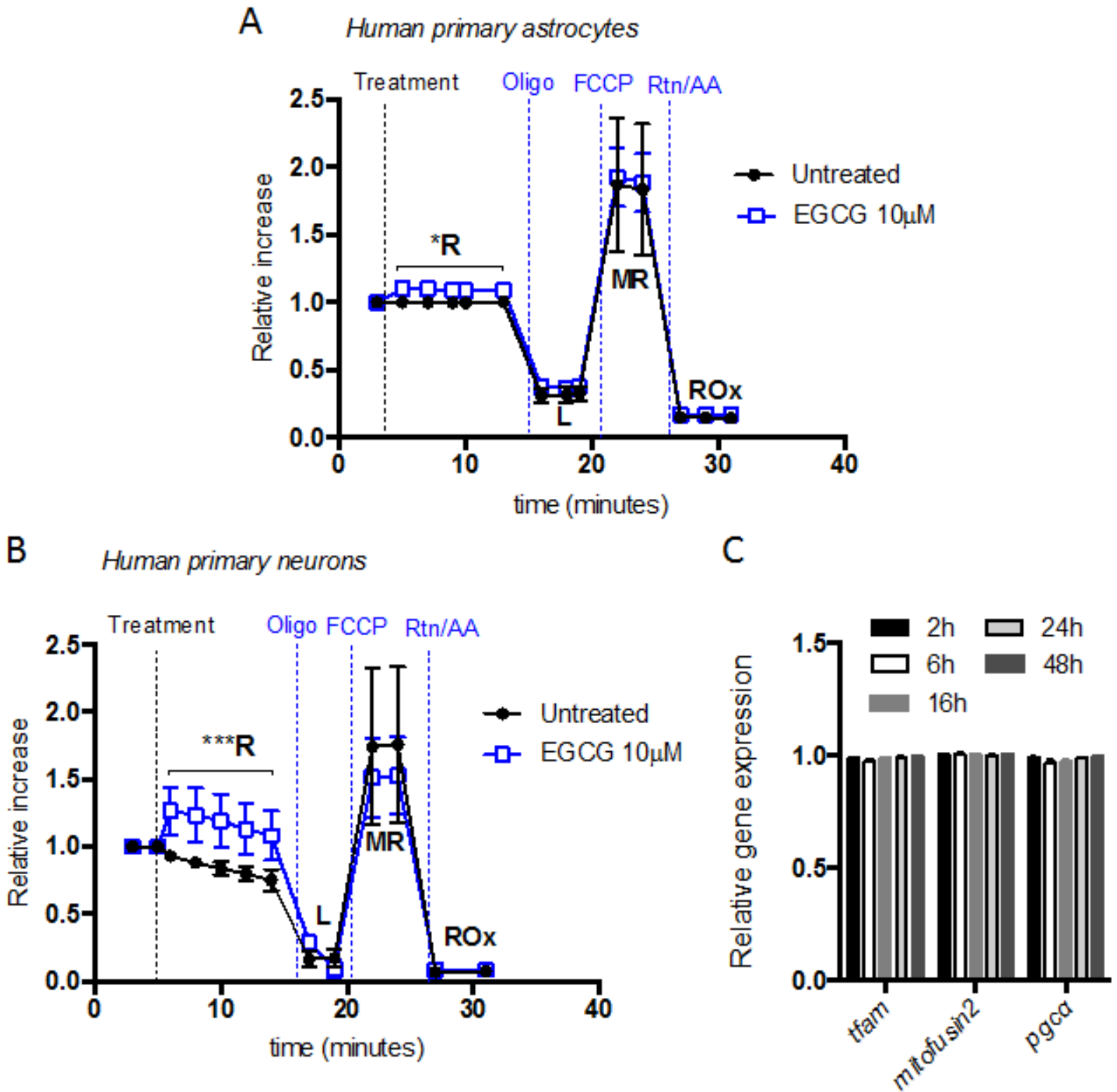

Figure 3: EGCG increases neuron and astrocytes routine respiration without altering mitochondrial biogenesis. $\mathrm{O}_{2}$ consumption rate $\left[\mathrm{pmol} \mathrm{O}_{2} / \mathrm{min}\right]$ of intact astrocytes $\mathbf{A}$. and neurons $\mathbf{B}$. showed by superimposed oxygraph traces from parallel measurements in two chambers. Treatment and mitochondrial inhibitors were added, at the time points indicated, in both chambers for the study of respiratory states. Data (means \pm s.e.m. of three experiments) are presented as cell number-specific oxygen flux in sample ((pmol $\mathrm{O}_{2} /$ $\mathrm{mim}) / 10^{6}$ cells) relative to cell number-specific oxygen flux during routine respiration before treatment. ${ }^{*} p \leq 0.05 * * * p \leq 0.005$ (Treatment versus none; Student's $t$-test). C. Mitochondrial biogenesis markers (Tfam and PGC- $\alpha$ ) and mitochondrial mass marker (Mitofusin2) gene transcript expression of human primary neurons after treatment with $10 \mu \mathrm{M}$ of EGCG at different time points. Data (means \pm s.e.m. of three experiments) are presented as normalized transcript expression in the samples relative to normalized transcript expression in untreated sample (Student's $t$-test). 
uncoupling (L), the increase in $\mathrm{O}_{2}$ consumption is probably linked to an increase in energy turnover.

Measuring mitochondrial respiration in intact cells allows the integration of mitochondrial quality (function) and quantity (density). To determine whether the changes observed in routine respiration were due to an increase in mitochondrial density, we measured expression of two key genes involved in mitochondrial biogenesis, PGC- $1 \alpha$ and Tfam as well as a marker of mitochondrial mass, mitofusin
2 [26]. Our results showed that EGCG did not influence mitochondrial biogenesis. It therefore suggests that the observed changes in mitochondrial respiration induced by EGCG were due to an increase of the mitochondrial functional properties (Figure 3C).
A

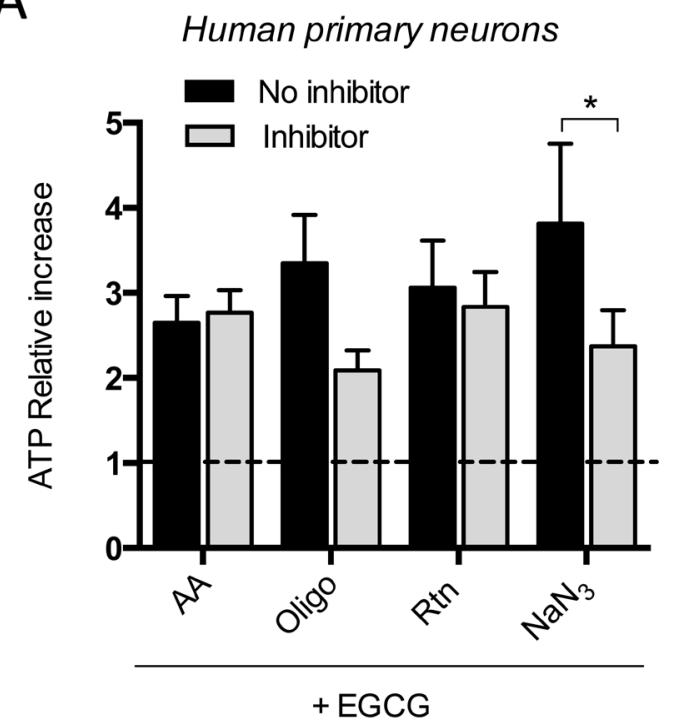

B

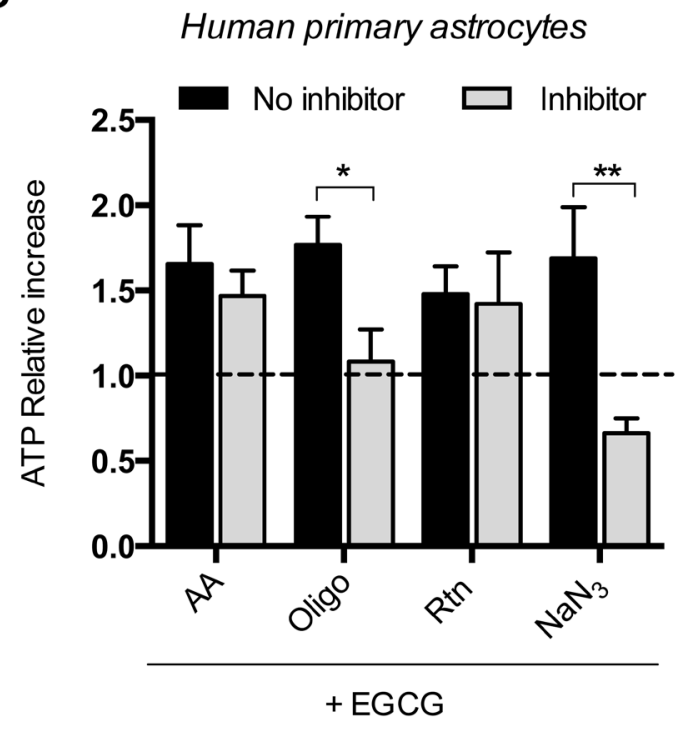

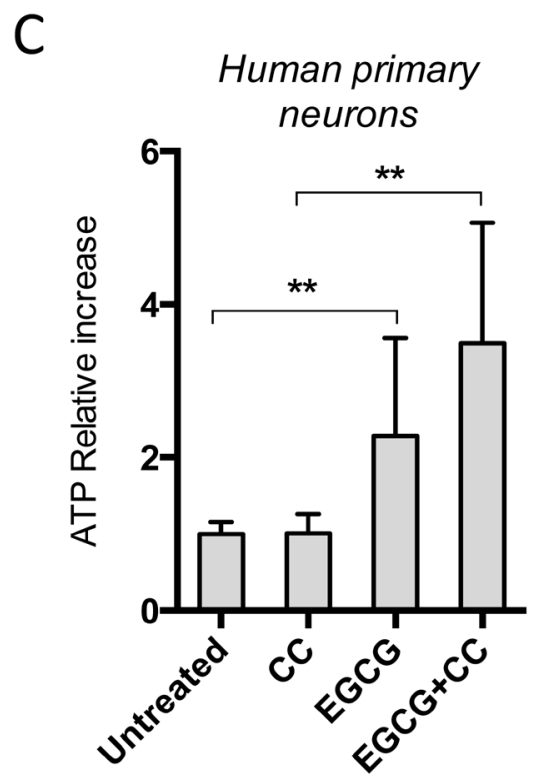

Figure 4: EGCG-dependent ATP increase is inhibited when complex IV is blocked in neurons and astrocytes. ATP production of neurons A. and astrocytes B. after treatment with $10 \mu \mathrm{M}$ EGCG for 16 and $2 \mathrm{~h}$, respectively, with or without specific mitochondrial complexes' inhibitors and assessed by luminescent intensity. Data (means \pm s.e.m. of three experiments) are presented as normalized mean intensity in sample relative to normalized mean intensity in the non-EGCG treated sample from each condition (no inhibitor and inhibitor without EGCG; fold change $=1$ ). ${ }^{*} p \leq 0.05,{ }^{*} p \leq 0.01$ (Student's $t$-test). C. ATP quantification of neurons after treatment with $10 \mu \mathrm{M}$ EGCG with or without $\mathrm{CC}$ for $16 \mathrm{~h}$ and assessed by luminescent intensity. Data (means \pm s.e.m. of three experiments) are presented as normalized mean intensity in sample relative to normalized mean intensity in untreated sample. ${ }^{*} p \leq 0.01, * * p \leq 0.005$ (Student's $t$-test). 


\section{EGCG-dependent ATP increase is inhibited when complex IV is blocked in neurons and astrocytes}

To establish whether EGCG enhances oxidative phosphorylation by directly activating a mitochondrial complex, we measured changes in EGCG-dependent intracellular ATP increase in the presence of different complexes' inhibitors. The time of treatments were chosen based on the previous kinetic studies, i.e. $16 \mathrm{~h}$ in neurons and $2 \mathrm{~h}$ in astrocytes. $\mathrm{NaN}_{3}$, a reversible inhibitor of complex IV, decreased the EGCG-dependent ATP production in neurons and astrocytes (Figure 4A, 4B). Moreover, when ATP synthase was irreversibly inhibited with oligomycin, a decrease in EGCG-dependent ATP
A

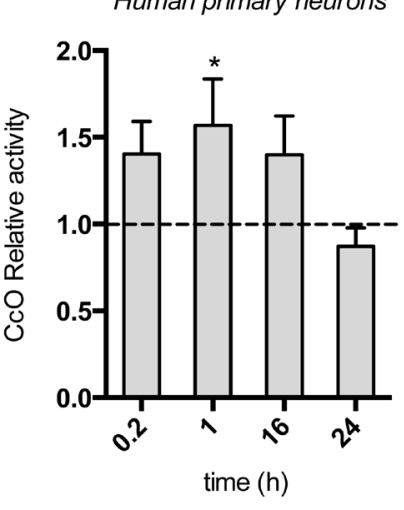

D

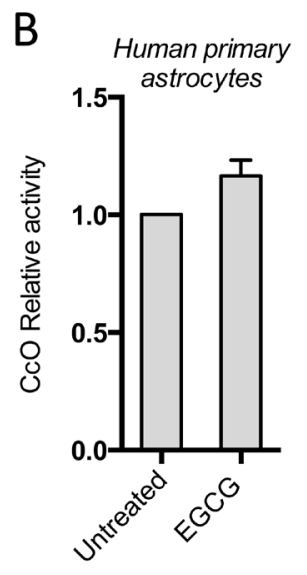

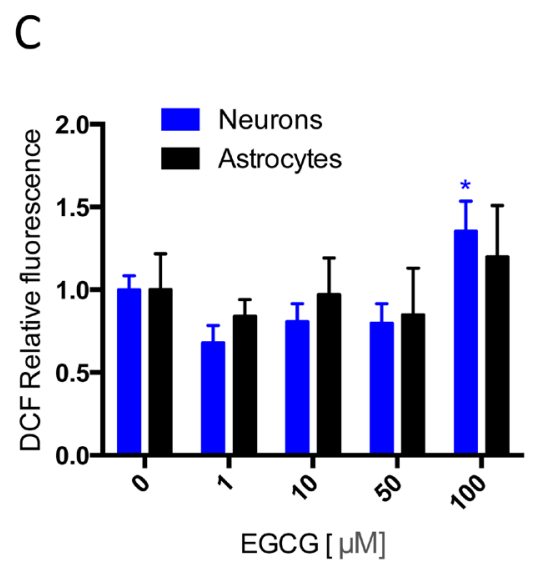

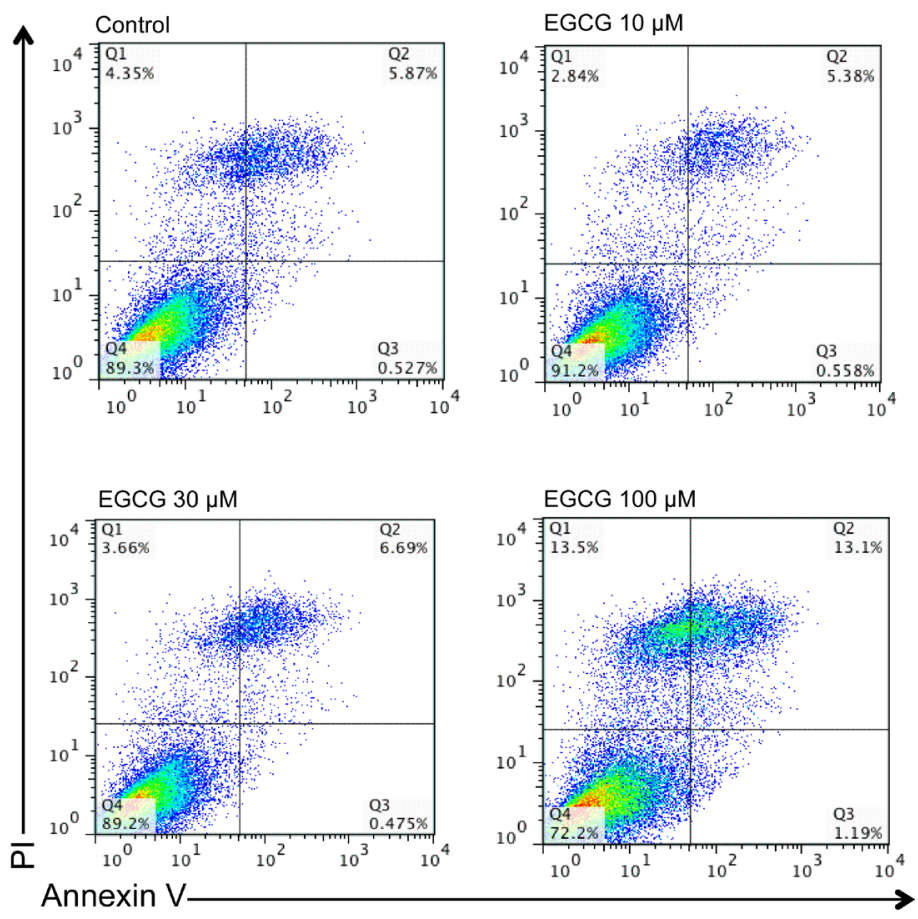

Figure 5: EGCG activates CcO activity without increasing oxidative stress or apoptosis. CcO activity of neurons and astrocytes after treatment with $10 \mu \mathrm{M}$ of EGCG at different time points A., B. assessed by the enzymatic degradation rate of cytochrome $\mathrm{c}$ and showed as relative increase of untreated. Data (means \pm s.e.m. of three experiments) are presented as normalized mean activity in sample relative to normalized mean activity in untreated sample for each time point. ${ }^{*} p \leq 0.01$ (Student's $t$-test). C. ROS production of neurons after treatment with different concentrations of EGCG (1-100 $\mu \mathrm{M})$ and assessed by DCF fluorescence intensity. Data (means \pm s.e.m. of three experiments) are presented as mean intensity in sample relative to mean intensity in untreated sample. ${ }^{*} p \leq 0.01$ (treatment versus none; Student's $t$-test). D. Apoptosis of astrocytes after treatment with 10-100 $\mu \mathrm{M}$ of EGCG for $48 \mathrm{~h}$ and assessed by cytofluorometric analysis. Data are from one experiment representative of two and shown in the top right quadrant as the frequency of cells positive for Annexin-V and PI in total astrocyte population. 
production was also observed. Although neither $\mathrm{NaN}_{3}$ nor oligomicyn completely blocked the effect of EGCG on ATP production in neurons, their effect was stronger in astrocytes.

We also tested whether EGCG-dependent ATP production could be mediated by activation of AMPK, using the AMPK pharmacological inhibitor, compound C (CC) [27]. CC did not inhibit the EGCG-induced ATP production in neurons (Figure 4C).

\section{EGCG activates $\mathrm{CcO}$ activity in neurons without concomitant increase of ROS production}

In order to confirm the direct effect of EGCG in $\mathrm{CcO}$ activity, we immunocaptured its cellular content and measured its activity by following the degradation rate of cytochrome $\mathrm{c}$ in cell cultures exposed to $10 \mu \mathrm{M}$ EGCG. We observed higher $\mathrm{CcO}$ activity in neurons treated with EGCG compared with the controls, but the increase of $\mathrm{CcO}$ activity in astrocytes was not-statistically significant (Figure 5A, 5B). This confirms that EGCG is activating $\mathrm{CcO}$ activity in neurons, but its activation in astrocytes may not be strong enough to be detected using this method.

Molecular oxygen is reduced to water in the $\mathrm{CcO}$ by a sequential four-electron transfer, however a minor proportion can be reduced by a 1-electron addition that occurs predominantly in the complex III but also in the complex I [28]. High $\Delta \psi_{\mathrm{m}}$ enhances the reduction of molecular oxygen to superoxide anion by complex I and III. Since EGCG is increasing $\mathrm{CcO}$ activity, the concomitant increase in $\Delta \psi_{\mathrm{m}}$ is expected to promote higher rates of mitochondrial superoxide. In order to verify this hypothesis, we therefore measured ROS production in EGCG treated neurons and astrocytes. Treatment with EGCG up to $50 \mu \mathrm{M}$ in both cell types did not increase ROS production, whereas $100 \mu \mathrm{M}$ increased ROS production in neurons (Figure 5C). Excessive ROS production is associated with induction of apoptosis. We therefore measured activation of apoptosis with Annexin $\mathrm{V}^{+} / \mathrm{PI}^{-}$ FACs analysis in astrocytes treated for $48 \mathrm{~h}$ with increasing

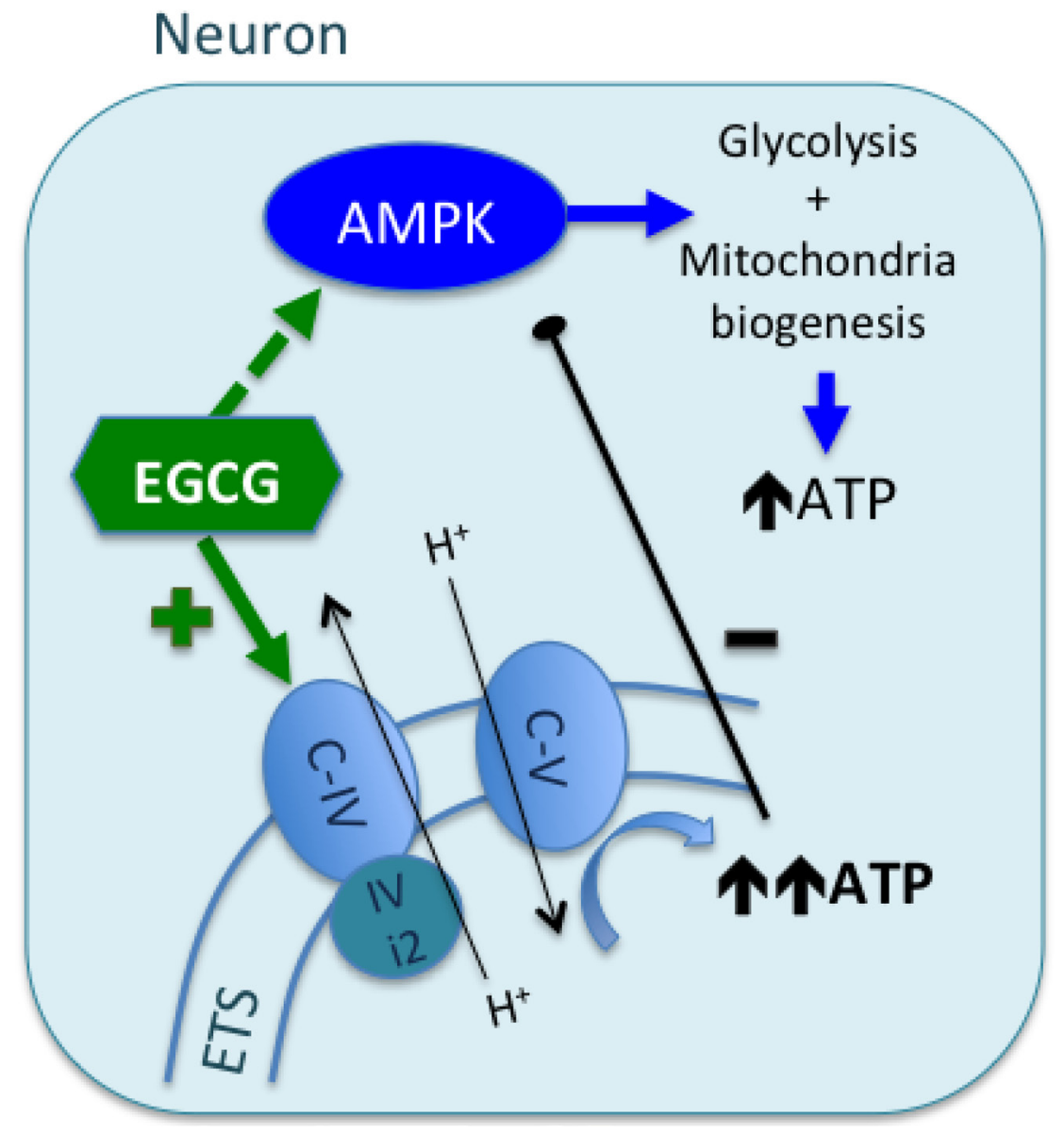

Figure 6: Proposed mechanism of EGCG activity in neurons. EGCG can cross the BBB and reach neuronal cytoplasm where it targets mitochondrial $\mathrm{CcO}(\mathrm{C}-\mathrm{IV})$. EGCG increases $\mathrm{CcO}$ activity by interacting with its physiological regulators or directly acting as an electron donor. Overall, activation of $\mathrm{CcO}$ leads to increase of ATP turnover by ATP synthase. High levels of ATP would be sensed by the subunit IV of $\mathrm{CcO}$, allosterically inhibiting its activity. However, neurons express the isoform 2 of the subunit IV (IVi2), which is not sensible to ATP increase (differently to astrocytes, which express the isoform 1, sensible to ATP increase). EGCG can also activate AMPK, but the rapid raise of mitochondrial ATP synthesis, decreases ADP:ATP ratio, which is an inhibitory signal for AMPK activity. 
concentrations of EGCG. We did not observed increased apoptosis $\left(\right.$ Annexin $\left.V^{+} / \mathrm{PI}^{-}\right)$or necrosis $\left(\right.$Annexin $\left.V^{+} / \mathrm{PI}^{+}\right)$in astrocytes treated with up to $30 \mu \mathrm{M}$ of EGCG compared with the control. However, both necrotic and apoptotic cells were increased in $100 \mu \mathrm{M}$ treatment with EGCG (Figure 5D). These results indicate that the induction of $\mathrm{CcO}$ by EGCG does not increase ROS production at the concentrations used in our study. Nonetheless, at higher doses the increase of $\Delta \psi_{\mathrm{m}}$ by $\mathrm{CcO}$ activation could be increasing superoxide production by complex I and III, which ultimately induces apoptosis and cell death.

\section{DISCUSSION}

The brain is highly vulnerable to energy and oxidative damage, which are the main contributing factors in the etiology of neurological disorders and ageing [29]. Therefore, restoring energy balance in the brain could be of paramount importance to improve several neurodegenerative diseases. In the current study, we demonstrated that EGCG induces energy turnover (ATP) by targeting $\mathrm{CcO}$ activity in the mitochondria of human cultured neurons and astrocytes. Several studies have suggested that EGCG can counteract mitochondrial dysfunction and oxidative stress mainly because of its antioxidant activity $[2,3]$, but to our knowledge our study is the first to show the effect of EGCG on $\mathrm{CcO}$ activity.

EGCG can specifically accumulate in the mitochondria of neurons and protect against oxidative stress, by acting as a natural free radical scavenger [2]. Accordingly, we observed that EGCG targets the mitochondria of two different neural cell types, inducing mitochondrial respiration. Our results are also consistent with previous studies showing that EGCG can rescue inflammatory cytokine-mediated reduction of ATP and $\Delta \psi_{\mathrm{m}}$ in insulin-producing $\beta$ cells [30], it can restore oligomeric Amyloid $\beta$ peptides-dependent impaired ATP levels, $\Delta \psi_{\mathrm{m}}$ and respiratory rates in neuroblastoma cell line and brain of AD mice model [1] and can recover mitochondria function in prion-treated neuroblastoma cell line [17]. Additionally, our data suggest that EGCG can potentiate ETS activity without inducing toxicity under physiological conditions in human cultured neurons and astrocytes.

Some studies have already linked the role of EGCG to energy metabolism as an agonist of AMPK [31-35]. AMPK is a crucial cellular energy sensor, which promotes ATP production when activated by switching on catabolic pathways while switching off anabolic or biosynthetic pathways (Reviewed by Mihayolva [36, 37]). AMPK can be activated by metabolic stresses that decrease ATP, but also through phosphorylation by Liver Kinase B (LKB) -1 complex or calmodium-dependent protein kinase kinase $\beta$ (CaMKK $\beta)$. CaMKK $\beta$ is important in the neural tissue because it senses increase in cytosolic $\mathrm{Ca}^{2+}$, which usually trigger ATP-consuming processes [38] and could therefore be a possible target for EGCG activity. Our results show that pharmacological inhibition of AMPK in human cultured neurons with $\mathrm{CC}$, which inhibits both LKB-1 and CaMKK $\beta$ - mediated AMPK activation, did not block EGCG-dependent ATP production. We also looked at the markers used to study changes in mitochondrial mass (mitofusin2) and biogenesis (PGC-1 $\alpha$ and Tfam), which have also been found to be up regulated by AMPK [27]. AMPK phosphorylates PGC-1 $\alpha$, which activates its own transcription [36]. We found that EGCG did not affect mRNA levels of any of those genes, indicating that the rapid increase in ATP production is not due to activation of AMPK-mediated mitochondrial biogenesis. However, we cannot discard that EGCG acts on AMPK and activates PGC-1 $\alpha[31,39]$. It is indeed possible that the fastest and first notable effect of EGCG is on ETSATP production resulting in an increase of ATP/ADP ratio that would be sensed by AMPK and would subsequently block its activation. In fact, when mitochondrial complex IV and $\mathrm{V}$ in the ETS are respectively inhibited by $\mathrm{NaN}_{3}$ and oligomycin, EGCG-mediated ATP production, even though reduced, is not completely blocked in human cultured neurons. This suggests that AMPK-mediated ATP production can be activated by EGCG when mitochondrial ATP turnover is blocked, thus maintaining the higher levels of ATP observed in neurons. The inhibitory effect of oligomycin and $\mathrm{NaN}_{3}$ on EGCG-mediated ATP production is stronger in human cultured astrocytes than in neurons. However, the variations observed between the two cell types could be due to differences in EGCG time of treatment. Longer treatment time in neurons could allow EGCG to activate secondary targets in different cellular metabolic pathways leading to ATP production. This would cover up the effects of the mitochondrial inhibitors blocking EGCG-mediated ATP synthesis through oxidative phosphorylation. Nevertheless, the divergence of metabolic regulation between neurons and astrocytes [40] should be also taken into account. Neurons main source of ATP is oxidative phosphorylation, whereas astrocytes rely on glycolysis [21]. This might explain why the EGCGmediated ATP production via the ETS had a greater impact in neurons than in astrocytes under the same treatment conditions. We also observed different kinetic properties for ATP production in neurons and astrocytes, which could also be explained by differences in $\mathrm{CcO}$ regulation in the two cell types. $\mathrm{CcO}$ is composed of 13 different subunits in mammals, which are encoded by both mitochondrial and genomic DNA [41]. Many of the nuclear subunits have different isoforms, which are differently induced and expressed according to the energy requirement of the tissue (Reviewed by Arnold [19]). Among them, subunit IV is a key regulator of $\mathrm{CcO}$, as it inhibits $\mathrm{CcO}$ when senses high ATP/ADP ratios [42]. Two isoforms of subunit IV (IV-1 and IV-2) have been described. CcO IV-1 is ubiquitously expressed in all tissues, whereas $\mathrm{CcO}$ IV-2 showed only high expression levels in adult lung and 
neurons, but not in astrocytes [43]. Neuronal CcO IV-2 abrogates allosteric inhibition of $\mathrm{CcO}$ by ATP, supporting a constantly high neuronal activity, whereas in astrocytes, which express CcO IV-1, ATP increase can block CcO [44, 45]. Our results show that EGCG induces an early increase of ATP in astrocytes (which resumes after 6h) as well as an exponential ATP increase in neurons (which raises over $48 \mathrm{~h}$ ). We believe that it could be explained by the ATP-mediated allosteric inhibition of $\mathrm{CcO}$ in astrocytes, but not in neurons, driven by the different isoforms of $\mathrm{CcO}$ subunit IV occurring in the two cell types. This also supports that EGCG-induced ATP increase in both cell types is mediated by an increase in ETS activity.

Another explanation for our results would be that EGCG could prevent inflammatory-induced iNOS overexpression and nitric oxide (NO) generation. It has been reported that $\mathrm{NO}$ can bind to the heme of $\mathrm{CcO}$ subunit II and inhibit its activity by competing with $\mathrm{O}_{2}[30,46]$. Therefore, EGCG could activate $\mathrm{CcO}$ by reducing $\mathrm{NO}-$ mediated inhibition of $\mathrm{CcO}$. However, the induction of $\mathrm{CcO}$ activity by EGCG was observed under physiological conditions when there is no increase of inflammatory stress, decreased oxygen levels or alteration on $\mathrm{CcO}$ affinity for oxygen. It is therefore unlikely that NO inhibition participates to the EGCG mechanisms of action for $\mathrm{CcO}$ activation. Other important regulators, which bind to different subunits of $\mathrm{CcO}$, such as the hormone sub-product 3,5-diiodothyronine [47], hypoxiainducible factor [48] or cardiolipin [49] are known to modulate $\mathrm{CcO}$ activity. Alternatively, processes such as phosphorylation [50], allosteric inhibition by proton gradient [51] or availability of substrates, ADP and oxygen also participate in $\mathrm{CcO}$ regulation. We believe that EGCG could influence these physiological regulators and interact with them, leading to an increase of $\mathrm{CcO}$ activity. Another possible mechanism to take into consideration is that EGCG could act as an electron donor to cytochrome c. EGCG has a reduction energy $\left(\mathrm{E}_{\mathrm{R}}\right)$ of $+0.43 \mathrm{eV}$ and has previously been shown to be able to transfer electrons to the nucleotide deoxyguanosine monophosphate (dGMP) [52]. EGCG would act similarly to $N, N, N^{\prime}, N^{\prime}$-Tetramethyl$p$-phenylenediamine (TMPD) $\left(\mathrm{E}_{\mathrm{R}}=+0.23 \mathrm{eV}\right)$, which is the artificial substrate used to reduce cytochrome $\mathrm{c}$ in respirometry assays for measuring $\mathrm{CcO}$ activity. EGCG is quite stable in aqueous solution under air [52], and would not easily go under auto-oxidation, as TMPD does, therefore making unnecessary the addition of ascorbate to maintain the reduced state of the electron donor. However, further studies need to be done to elucidate the mechanistic basis of EGCG effect on the activation of $\mathrm{CcO}$.

EGCG has been shown to act as an antioxidant, reducing ROS induced by neurotoxic compounds [3]. In this study, we also show that used at low concentrations, it increases $\mathrm{CcO}$ activity and ATP synthesis without inducing ROS production, cytotoxicity or apoptosis. Specifically, our results provide compelling evidences that EGCG targets mitochondria of human cultured neurons and astrocytes, activating $\mathrm{CcO}$ and increasing ATP turnover without affecting the redox state of the cell (Figure 6). This natural compound may therefore be a potential interesting candidate to counteract mitochondrial dysfunction and oxidative stress observed in many neurodegenerative diseases.

\section{MATERIALS AND METHODS}

\section{Cell culture}

Human fetal brains were obtained from 1619 week-old fetuses collected following therapeutic termination with informed consent. This protocol has been approved by the Human Ethics Committees of Macquarie University (Ethic approval: 5201300330). Mixed brain cell suspension was prepared using a protocol previously described by Guillemin [53]. Briefly, neurons were cultured by plating the mixed cell suspension in culture dishes or glass coverslips coated with Matrigel Matrix (1:20 in Neurobasal Medium; Corning) and maintained in Neurobasal Medium supplemented with 1\% B-27 supplement, 1\% GlutaMAX, 1\% Antibiotic/Antimycotic, $0.5 \%$ HEPES buffer and $5 \mathrm{mM}$ glucose for $7-10$ days at $37^{\circ} \mathrm{C}$ in a humidified atmosphere containing $5 \% \mathrm{CO}_{2}$ $[54,55]$. Astrocytes were obtained by seeding high density mixed brain cell suspension in a cell culture flask. Attached cells were washed with PBS and new medium was added twice per week. When the desired confluence was achieved, cells were trypsinized and expanded. Astrocytes were maintained in RPMI medium supplemented with $10 \%$ fetal calf serum (FCS), $1 \%$ GlutaMAX and $1 \%$ Antibiotic/Antimycotic at $37^{\circ} \mathrm{C}$ in a humidified atmosphere containing 5\% $\mathrm{CO}_{2}[56-$ 58]. All cell culture reagents were obtained from Life Technologies.

\section{ATP- luminescent measurements}

Several natural compounds were screened for their ability to induce ATP-turnover. Treatment with kynurenic acid (KYNA) $(10 \mu \mathrm{M})$, Phyllantus Emblica $(30 \mu \mathrm{g} / \mathrm{mL})$, Pomegranate $(30 \mu \mathrm{g} / \mathrm{mL})$, Curcuma Longa. $(30 \mu \mathrm{g} / \mathrm{mL})$, Berberine $(30 \mu \mathrm{M})$ or EGCG $(30 \mu \mathrm{M})$ (Cayman Chemical) was done for 2 and $24 \mathrm{~h}$ in human cultured neurons. Among the different natural compounds tested, EGCG showed the most significant increase in intracellular ATP production in human cultured neurons (Supplementary Figure 1) and was therefore selected for further analysis. For EGCG-ATP kinetics induction studies, cells were treated with $10 \mu \mathrm{M}$ of EGCG in the appropriate culture 
medium at different time points. For dose-dependent studies increasing concentrations of EGCG in the appropriate culture medium were added for $24 \mathrm{~h}$ in neurons and $2 \mathrm{~h}$ in astrocytes. For ATP depletion studies, cells were treated with $2.5 \mu \mathrm{M}$ antimycin $\mathrm{A}$ (AA), $1 \mu \mathrm{M}$ of rotenone (Rtn), $5 \mu \mathrm{M}$ of oligomycin (Oligo), $10 \mathrm{mM}$ of $\mathrm{NaN}_{3}$ and $10 \mu \mathrm{M}$ of CC. All reagents were obtained from SigmaAldrich. Treatment with the inhibitors was performed 1h before treatment with EGCG. Controls were treated with equal amount of the solvent used for each treatment. After treatments, the cells were immediately washed with warm PBS, harvested in PBS and assessed for intracellular total ATP production using a commercially available luciferase-luciferin system (ATPlite; Perkin Elmer) in a PHERAstar plate reader (BMG labtech, Ortenberg, Germany). Briefly, harvested cells were lysed by repeated freeze and thaw cycles and centrifuged at $10,000 \mathrm{~g}$ for 10 minutes; the supernatant was collected and used for ATP measurements and protein quantification. All experiments were performed using a minimum of $1 \mathrm{mg} / \mathrm{mL}$ of cell protein lysate. Protein measurements were determined using Pierce BCA protein assay Kit (Thermo scientific). Total ATP was normalized against total protein to account for any difference in cell density.

\section{Cytotoxicity}

The release of $\mathrm{LDH}$ in the culture supernatant correlates with the amount of cell death and membrane damage, providing an accurate measure of cellular toxicity [59]. LDH activity was measured in parallel with the ATP. It was assayed using the commercial CytoTox 96 (Promega) cytotoxicity assay following the manufacturer's specifications. LDH activity in the supernatants was normalized against total cell protein to account for any difference in cell density.

\section{Assessment of mitochondrial membrane potential}

$\Delta \Psi_{\mathrm{m}}$ was determined using rhodamine 123 (R123; Life Technologies), as described [60], with slight modifications. Neurons or astrocytes cultures in 12 well plates were treated at different time points with $10 \mu \mathrm{M}$ of EGCG in culture medium. Then, cells were washed with warm PBS and incubated with $10 \mu \mathrm{M}$ of R123 (quenching mode) in Leibovitz's (L-15) Medium (Life Technologies) supplemented with $5 \mathrm{mM}$ of glucose for 20 minutes at $37^{\circ} \mathrm{C}$ in a humidified atmosphere containing $5 \% \mathrm{CO}_{2}$. In quenching mode, the probe will accumulate within the mitochondria forming aggregates that quench some of the fluorescent emission of the dye. The R123-containing medium was removed and cells were washed with PBS and further incubated in warm L-15 Medium supplemented with $5 \mathrm{mM}$ of glucose at $37^{\circ} \mathrm{C}$ for 15 minutes. Treatmentinduced mitochondrial depolarization (increase in $\Delta \Psi_{\mathrm{m}}$ ) results in the release of the dye, thus unquenching the dye and increasing the fluorescence signal. The sample was immediately placed in the PHERAstar plate reader at $37^{\circ} \mathrm{C}$ with excitation and emission set at 560 and $645 \mathrm{~nm}$ respectively. Mean fluorescence intensity was measured using orbital averaging to account for uneven cell distribution across the well.

$\Delta \Psi_{\mathrm{m}}$ was also determined using CMXRosamine probe (CMXRos; MitoTracker Red, Life Technologies) according to previous studies showing that an increase in $\Delta \Psi_{\mathrm{m}}$ lead to an increase of CMXRos fluorescence intensity [22]. Briefly, neurons cultured in glass coverslips were treated at different time points with $10 \mu \mathrm{M}$ of EGCG in culture medium. Then cells were washed with warm PBS prior to add 50nM of CMXRos in L-15 Medium supplemented with $5 \mathrm{mM}$ of glucose. Cells were incubated for 30 minutes at $37^{\circ} \mathrm{C}$ in a humidified atmosphere containing $5 \% \mathrm{CO}_{2}$, then washed with warm PBS and immediately fixed with $4 \%$ paraformaldehyde (SigmaAldrich) for 15 minutes at room temperature. Nuclear staining was performed by incubating the cells with 4,6-diamidino-2-phenylindole (DAPI; Sigma-Aldrich) at $1 \mathrm{mg} / \mathrm{mL}$ for 1 minute at room temperature. Then, after washing with PBS, the coverslips were mounted on glass slides with Fluoromount-G (eBioscience). Epifluorescence images were obtained on an Olympus FV1000 confocal microscope (Olympus, Victoria, Australia) captured with a Charged-Coupled Device image sensor. For each coverslip, ten randomly selected fields were acquired using the same settings along each experiment. After background correction, fluorescence intensity for CMXRos was measured for each condition using ImageJ software [61]. Mean fluorescence intensity was normalized against the total number of intact cells, determined by DAPI nuclear label.

\section{Mitochondrial respiration in intact cells}

Oxygen consumption in intact cells was measured using the high-resolution respirometer Oxygraph-2K (Oroboros instruments, Innsburk, Austria). Zero oxygen measurements were taken after injection of sodium dithionite and polarographic oxygen sensors were calibrated with air-saturated culture medium at $37^{\circ} \mathrm{C}$. Intact cells were removed from the tissue culture dish with TripE (Life Technologies) and after one wash with PBS, 5 $\mathrm{x} 10^{6}$ cells were added to $2 \mathrm{~mL}$ of normal culture medium. Cell suspension was immediately placed in the oxygraph chamber at $37^{\circ} \mathrm{C}$ under continuous stirring at 300rpm. After monitoring routine respiration (R) sequential injections of the following chemicals were performed to evaluate different mitochondrial respiration rates: oligomycin $(5 \mu \mathrm{M})$ to inhibit ATP synthase and measure the proton leak (L); FCCP $(4 \mu \mathrm{M})$ a protonophoric uncoupler to evaluate the ETS maximum capacity (MR); and rotenone $(1 \mu \mathrm{M})$ and antimycin $\mathrm{A}(2.5 \mu \mathrm{M})$ to inhibit 
Table 1: Primers used in qPCR

\begin{tabular}{|l|l|l|}
\hline Gene & Forward sequence & Reverse Sequence \\
\hline Tfam & 5'-CCTGCTCGGAGCTTCTCAAA-3' & 5'-ACCCTTGGGGTCATTTGGTG-3' \\
\hline PGC-1 $\alpha$ & 5'-AGAACAGCTAACTCCAAGTCAGATT-3' & 5'-CTTCAGCTTTTCCTGCGGTGAAT-3' \\
\hline PGK-1 & 5'-TCACTCGGGGCTAAGCAGATT-3' & 5'-CAGTGCTCACATGGCTGACT-3' \\
\hline TBP & 5'-GGGAGCTGTGATGTGAAGT-3' & 5'-GGAGGCAAGGGTACATGAGA-3' \\
\hline Mitofusin2 & 5'-ACCCTGATGCAGACGGAAAA-3' & 5'-ACCAGGAAGCTGGTACAACG-3' \\
\hline
\end{tabular}

complex I and complex III respectively and to measure the residual oxygen consumption ( $\mathrm{ROx}$ ).

\section{qPCR}

Total RNA from cells and tissue was prepared from RNeasy Miniprep kit according to manufacturer's instructions. cDNA was prepared by using $1 \mu \mathrm{g}$ of RNA per reaction. Standard reverse transcription (RT) was performed using SuperScript VILO cDNA Synthesis Kit according to manufacturer's instructions. qPCR analysis was carried out on the Viia7 Real-Time PCR system (Applied Biosystems, NSW, Australia) using SYBR Select Master Mix. All reagents were obtained from Life Technologies. Initial enzyme activation was performed at $95^{\circ} \mathrm{C}$ for 5 minutes, followed by 40 cycles of denaturation at $95^{\circ} \mathrm{C}$ for 5 seconds, and primer annealing/ extension at $60^{\circ} \mathrm{C}$ for 20 seconds. Melting curve analysis was performed at $95^{\circ} \mathrm{C}$ for 1 minute, $60^{\circ} \mathrm{C}$ for 30 seconds and $95^{\circ} \mathrm{C}$ for 30 seconds at the end of each run to confirm a single PCR product in each reaction. The relative expression of peroxisome proliferator-activated receptor $\Upsilon$ coactivator $1 \alpha(\mathrm{PGC}-1 \alpha)$, mitochondrial transcription factor A (Tfam) and Mitofusin2 was normalized against the housekeeping genes TATA-binding protein (TBP) and phosphoglycerate kinase (PGK)-1. Primer sequences used for qPCR are shown in Table 1.

\section{Mitochondrial complex IV content and activity}

The activity of complex IV (cytochrome c oxidase) was measured by using the Mitosciences Human complex IV activity micro plate assay Kit (Abcam) according to the manufacturer's instructions. Briefly, cells were lysed and BCA assay was used to measure total protein content. The same amount of protein was loaded in each condition $(\approx 100 \mu \mathrm{g})$. Complex IV was immunocaptured with $\mathrm{CcO}$ antibody and the activity was measured by the oxidation rate of reduced cytochrome $c$ at $550 \mathrm{~nm}$, using PHERAstar plate reader.

\section{ROS production with DCF}

Intracellular oxidative stress was assessed by monitoring $\mathrm{H}_{2} \mathrm{O}_{2}$ (indicative of ROS generation). The amount of $\mathrm{H}_{2} \mathrm{O}_{2}$ can be estimated by the 2-,7-dichlorofluorescin (DCF)- $\mathrm{H}_{2}$ dye (Life Technologies), which oxidizes in the presence of $\mathrm{H}_{2} \mathrm{O}_{2}$ to its fluorescent product DCF [62]. Astrocytes and neurons were pretreated with varying concentrations of EGCG $(1-100 \mu \mathrm{M})$ for $2 \mathrm{~h}$ (astrocytes) and 24h (neurons). After washing twice with PBS, cells were incubated with $10 \mu \mathrm{M} \mathrm{DCF-H_{2 }}$ in L-15 Medium supplemented with 5mM of glucose for 30 minutes at $37^{\circ} \mathrm{C}$ in a humidified atmosphere containing $5 \% \mathrm{CO}_{2}$. Then, cells were washed twice with PBS and pre-warmed L-15 Medium supplemented with $5 \mathrm{mM}$ of glucose and 1\% FCS was added. The fluorescence intensity was immediately measured at $37^{\circ} \mathrm{C}$ using orbital averaging in the PHERAstar plate reader with excitation and emission wavelengths set at $485 \mathrm{~nm}$ and $530 \mathrm{~nm}$ respectively.

\section{Apoptosis}

Apoptosis was measured quantitatively using Annexin-V FITC (BD Biosciences) and propidium iodide. This protocol numerates early apoptotic cells by probing for cell surface exposed phosphatidylserine (PS) with FITC labeled Annexin-V and for plasma membrane integrity by propidium iodide (PI). Cells were treated with EGCG at different concentrations for $24 \mathrm{~h}$ and with tumor necrosis factor (TNF)- $\alpha$ as an apoptotic positive control for $48 \mathrm{~h}$. Recovered cells were suspended in $1 \mathrm{X}$ binding buffer and Annexin-V FITC and propidium iodide were added prior to flow cytometry analysis.

\section{Data analysis}

All in vitro determinations are presented as means \pm the standard error of the mean (s.e.m.) from at least three independent experiments, unless otherwise indicated. Student's $t$-test (two-sided and paired) was used for two-group analysis, performing separate Student's $t$-test 
in multi-group analysis. All analyses were conducted using GraphPad Prism software (version 3.0; GraphPad Software). Statistical significance was accepted at $\mathrm{p}<0.05$.

\section{ACKNOWLEDGEMENTS}

This work was supported by the National Health and Medical Research Council (NHMRC) and the Ramaciotti Perpetual Foundation (Australia). Guillemin GJ is the recipient of the Australian Research Council (ARC) Future Fellowship and Gloria Castellano was a recipient of the Macquarie University international scholarship.

\section{CONFLICTS OF INTEREST}

The authors declare no conflict of interests in regards to this manuscript.

\section{Authors' contribution}

GCG designed and conducted all the experiments and wrote the manuscript. HM and WOB provided conceptual help and reagents throughout experimentation. $\mathrm{AB}$ contributed to specific experimental designs. NP made possible and design mitochondrial studies, and contributed to the manuscript writing. GJG was involved in conception and design, data analysis and interpretation, manuscript writing and final approval of the manuscript.

\section{Editorial note}

This paper has been accepted based in part on peerreview conducted by another journal and the authors' response and revisions as well as expedited peer-review in Oncotarget.

\section{REFERENCES}

1. Dragicevic N, Smith A, Lin X, Yuan F, Copes N, Delic V, Tan J, Cao C, Shytle RD and Bradshaw PC. Green tea epigallocatechin-3-gallate (EGCG) and other flavonoids reduce Alzheimer's amyloid-induced mitochondrial dysfunction. Journal of Alzheimer's disease : JAD. 2011; 26:507-521.

2. Schroeder EK, Kelsey NA, Doyle J, Breed E, Bouchard RJ, Loucks FA, Harbison RA and Linseman DA. Green tea epigallocatechin 3-gallate accumulates in mitochondria and displays a selective antiapoptotic effect against inducers of mitochondrial oxidative stress in neurons. Antioxidants \& redox signaling. 2009; 11:469-480.

3. Valenti D, De Rasmo D, Signorile A, Rossi L, de Bari L, Scala I, Granese B, Papa S and Vacca RA. Epigallocatechin3-gallate prevents oxidative phosphorylation deficit and promotes mitochondrial biogenesis in human cells from subjects with Down's syndrome. Biochimica et biophysica acta. 2013 ; 1832:542-552.

4. Prochazkova D, Bousova I and Wilhelmova N. Antioxidant and prooxidant properties of flavonoids. Fitoterapia. 2011; 82:513-523.

5. Murakami A and Ohnishi K. Target molecules of food phytochemicals: food science bound for the next dimension. Food \& function. 2012; 3:462-476.

6. Cusi MG, Del Vecchio MT, Terrosi C, Savellini GG, Di Genova G, La Placa M, Fallarino F, Moser C, Cardone C, Giorgi G, Francini G and Correale P. Immunereconstituted influenza virosome containing CD40L gene enhances the immunological and protective activity of a carcinoembryonic antigen anticancer vaccine. Journal of Immunology. 2005; 174:7210-7216.

7. Takahashi A, Watanabe T, Mondal A, Suzuki K, KurusuKanno M, Li Z, Yamazaki T, Fujiki H and Suganuma M. Mechanism-based inhibition of cancer metastasis with (-)-epigallocatechin gallate. Biochem Biophys Res Commun. 2014; 443:1-6.

8. Katiyar S, Elmets CA and Katiyar SK. Green tea and skin cancer: photoimmunology, angiogenesis and DNA repair. The Journal of nutritional biochemistry. 2007; 18:287-296.

9. Singh $\mathrm{T}$ and Katiyar SK. Green tea catechins reduce invasive potential of human melanoma cells by targeting COX-2, PGE2 receptors and epithelial-to-mesenchymal transition. PLoS One. 2011; 6:e25224.

10. Singh BN, Shankar S and Srivastava RK. Green tea catechin, epigallocatechin-3-gallate (EGCG): mechanisms, perspectives and clinical applications. Biochem Pharmacol. 2011; 82:1807-1821.

11. Fu Z, Zhen W, Yuskavage J and Liu D. Epigallocatechin gallate delays the onset of type 1 diabetes in spontaneous non-obese diabetic mice. The British journal of nutrition. 2011; 105:1218-1225.

12. Mandel SA, Avramovich-Tirosh Y, Reznichenko L, Zheng $\mathrm{H}$, Weinreb $\mathrm{O}$, Amit $\mathrm{T}$ and Youdim MB. Multifunctional activities of green tea catechins in neuroprotection. Modulation of cell survival genes, iron-dependent oxidative stress and PKC signaling pathway. Neurosignals. 2005; 14:46-60.

13. Zhang HS, Wu TC, Sang WW and Ruan Z. EGCG inhibits Tat-induced LTR transactivation: role of Nrf2, AKT, AMPK signaling pathway. Life Sci. 2012; 90:747-754.

14. Narkar VA, Downes M, Yu RT, Embler E, Wang YX, Banayo E, Mihaylova MM, Nelson MC, Zou Y, Juguilon H, Kang H, Shaw RJ and Evans RM. AMPK and PPARdelta agonists are exercise mimetics. Cell. 2008; 134:405-415.

15. Rietveld A and Wiseman S. Antioxidant effects of tea: evidence from human clinical trials. The Journal of nutrition. 2003; 133:3285S-3292S.

16. Lin LC, Wang MN, Tseng TY, Sung JS and Tsai TH. Pharmacokinetics of (-)-epigallocatechin-3-gallate in conscious and freely moving rats and its brain regional 
distribution. J Agric Food Chem. 2007; 55:1517-1524.

17. Lee JH, Moon JH, Kim SW, Jeong JK, Nazim UM, Lee YJ, Seol JW and Park SY. EGCG-mediated autophagy flux has a neuroprotection effect via a class III histone deacetylase in primary neuron cells. Oncotarget. 2015; 6: 9701-17. doi: 10.18632/oncotarget.3832..

18. Srinivasan S and Avadhani NG. Cytochrome c oxidase dysfunction in oxidative stress. Free Radical Biology and Medicine. 2012; 53:1252-1263.

19. Arnold S. The power of life. Cytochrome c oxidase takes center stage in metabolic control, cell signalling and survival. Mitochondrion. 2012; 12:46-56.

20. Perry SW, Norman JP, Barbieri J, Brown EB and Gelbard HA. Mitochondrial membrane potential probes and the proton gradient: a practical usage guide. BioTechniques. 2011; 50:98-115.

21. Fernandez-Fernandez S, Almeida A and Bolaños JP. Antioxidant and bioenergetic coupling between neurons and astrocytes. Biochemical Journal. 2012; 443:3-11.

22. Pendergrass W, Wolf $\mathrm{N}$ and Poot M. Efficacy of MitoTracker Green ${ }^{\mathrm{TM}}$ and CMXrosamine to measure changes in mitochondrial membrane potentials in living cells and tissues. Cytometry Part A. 2004; 61A:162-169.

23. Nicholls DG and Budd SL. Mitochondria and Neuronal Survival. Physiol Rev. 2000; 80:315-60.

24. Hutter E, Unterluggauer H, Garedew A, Jansen-Durr P and Gnaiger E. High-resolution respirometry--a modern tool in aging research. Experimental gerontology. 2006; 41:103109.

25. Pesta D and Gnaiger E. High-resolution respirometry: OXPHOS protocols for human cells and permeabilized fibers from small biopsies of human muscle. Methods in molecular biology. 2012; 810:25-58.

26. Kelly DP and Scarpulla RC. Transcriptional regulatory circuits controlling mitochondrial biogenesis and function. Genes \& development. 2004; 18:357-368.

27. Dasgupta B and Milbrandt J. Resveratrol stimulates AMP kinase activity in neurons. Proc Natl Acad Sci U S A. 2007; 104:7217-7222.

28. Sugioka K, Nakano M, Totsune-Nakano H, Minakami $\mathrm{H}$, Tero-Kubota S and Ikegami Y. Mechanism of O2generation in reduction and oxidation cycle of ubiquinones in a model of mitochondrial electron transport systems. Biochimica et biophysica acta. 1988; 936:377-385.

29. Jellinger KA. Basic mechanisms of neurodegeneration: a critical update. Journal of cellular and molecular medicine. 2010; 14:457-487.

30. Zhang Z, Ding Y, Dai X, Wang J and Li Y. Epigallocatechin-3-gallate protects pro-inflammatory cytokine induced injuries in insulin-producing cells through the mitochondrial pathway. Eur J Pharmacol. 2011; 670:311-316.

31. Collins QF, Liu HY, Pi J, Liu Z, Quon MJ and Cao W. Epigallocatechin-3-gallate (EGCG), a green tea polyphenol, suppresses hepatic gluconeogenesis through 5'-AMPactivated protein kinase. The Journal of biological chemistry. 2007; 282:30143-30149.

32. Hwang JT, Ha J, Park IJ, Lee SK, Baik HW, Kim YM and Park OJ. Apoptotic effect of EGCG in HT-29 colon cancer cells via AMPK signal pathway. Cancer letters. 2007; 247:115-121.

33. Huang CH, Tsai SJ, Wang YJ, Pan MH, Kao JY and Way TD. EGCG inhibits protein synthesis, lipogenesis, and cell cycle progression through activation of AMPK in p53 positive and negative human hepatoma cells. Molecular nutrition \& food research. 2009; 53:1156-1165.

34. Park SY, Jung CH, Song B, Park OJ and Kim YM. Proapoptotic and migration-suppressing potential of EGCG, and the involvement of AMPK in the p53-mediated modulation of VEGF and MMP-9 expression. Oncology letters. 2013; 6:1346-1350.

35. Chen C, Shen G, Hebbar V, Hu R, Owuor ED and Kong AN. Epigallocatechin-3-gallate-induced stress signals in HT-29 human colon adenocarcinoma cells. Carcinogenesis. 2003; 24:1369-1378.

36. Hardie DG, Ross FA and Hawley SA. AMPK: a nutrient and energy sensor that maintains energy homeostasis. Nat Rev Mol Cell Biol. 2012; 13:251-262.

37. Mihaylova MM and Shaw RJ. The AMPK signalling pathway coordinates cell growth, autophagy and metabolism. Nature cell biology. 2011; 13:1016-1023.

38. Spasic MR, Callaerts $P$ and Norga KK. AMP-activated protein kinase (AMPK) molecular crossroad for metabolic control and survival of neurons. The Neuroscientist. 2009; 15:309-316.

39. Wagner AE, Piegholdt S, Rabe D, Baenas N, Schloesser A, Eggersdorfer M, Stocker A and Rimbach G. Epigallocatechin gallate affects glucose metabolism and increases fitness and lifespan in Drosophila melanogaster. Oncotarget. 2015; 6:30568-78. doi: 10.18632/ oncotarget.5215.

40. Dinuzzo M, Mangia S, Maraviglia B and Giove F. The role of astrocytic glycogen in supporting the energetics of neuronal activity. Neurochem Res. 2012; 37:2432-2438.

41. Ludwig B, Bender E, Arnold S, Huttemann M, Lee I and Kadenbach B. Cytochrome $\mathrm{C}$ oxidase and the regulation of oxidative phosphorylation. Chembiochem. 2001; 2:392403.

42. Arnold $\mathrm{S}$ and Kadenbach $\mathrm{B}$. The intramitochondrial ATP/ADP-ratio controls cytochrome c oxidase activity allosterically. FEBS Lett. 1999; 443:105-108.

43. Huttemann M, Kadenbach B and Grossman LI. Mammalian subunit IV isoforms of cytochrome c oxidase. Gene. 2001; 267:111-123.

44. Misiak M, Singh S, Drewlo S, Beyer C and Arnold S. Brain region-specific vulnerability of astrocytes in response to 3-nitropropionic acid is mediated by cytochrome c oxidase isoform expression. Cell and tissue research. 2010; 341:83- 
93.

45. Horvat S, Beyer C and Arnold S. Effect of hypoxia on the transcription pattern of subunit isoforms and the kinetics of cytochrome c oxidase in cortical astrocytes and cerebellar neurons. J Neurochem. 2006; 99:937-951.

46. Collman JP, Dey A, Barile CJ, Ghosh S and Decreau RA. Inhibition of electrocatalytic $\mathrm{O}(2)$ reduction of functional $\mathrm{CcO}$ models by competitive, non-competitive, and mixed inhibitors. Inorganic chemistry. 2009; 48:10528-10534.

47. Arnold S, Goglia F and Kadenbach B. 3,5-Diiodothyronine binds to subunit Va of cytochrome-c oxidase and abolishes the allosteric inhibition of respiration by ATP. European journal of biochemistry. 1998; 252:325-330.

48. Fukuda R, Zhang H, Kim JW, Shimoda L, Dang CV and Semenza GL. HIF-1 regulates cytochrome oxidase subunits to optimize efficiency of respiration in hypoxic cells. Cell. 2007; 129:111-122.

49. Pope S, Land JM and Heales SJ. Oxidative stress and mitochondrial dysfunction in neurodegeneration; cardiolipin a critical target? Biochimica et biophysica acta. 2008; 1777:794-799.

50. Helling S, Huttemann M, Ramzan R, Kim SH, Lee I, Muller T, Langenfeld E, Meyer HE, Kadenbach B, Vogt S and Marcus K. Multiple phosphorylations of cytochrome c oxidase and their functions. Proteomics. 2012; 12:950-959.

51. Piccoli C, Scrima R, Boffoli D and Capitanio N. Control by cytochrome $\mathrm{c}$ oxidase of the cellular oxidative phosphorylation system depends on the mitochondrial energy state. The Biochemical journal. 2006; 396:573-583.

52. $\mathrm{Lu} \mathrm{LY}, \mathrm{Ou} \mathrm{N}$ and $\mathrm{Lu}$ QB. Antioxidant induces DNA damage, cell death and mutagenicity in human lung and skin normal cells. Scientific reports. 2013; 3:3169.

53. Guillemin GJ, Smythe G, Takikawa O and Brew BJ. Expression of indoleamine 2,3-dioxygenase and production of quinolinic acid by human microglia, astrocytes, and neurons. Glia. 2005; 49:15-23.

54. Guillemin GJ, Cullen KM, Lim CK, Smythe GA, Garner B, Kapoor V, Takikawa O and Brew BJ. Characterization of the Kynurenine Pathway in Human Neurons. The Journal of Neuroscience. 2007; 27:12884-12892.

55. Braidy N, Grant R, Adams S and Guillemin GJ. Neuroprotective effects of naturally occurring polyphenols on quinolinic acid-induced excitotoxicity in human neurons. FEBS Journal. 2010; 277:368-382.

56. Ting KK, Brew BJ and Guillemin GJ. (2007). Effect of quinolinic acid on gene expression in human astrocytes: Implications for Alzheimer's disease. In: Takai K, ed., pp. 384-388.

57. Guillemin GJ, Croitoru-Lamoury J, Dormont D, Armati PJ and Brew BJ. Quinolinic acid upregulates chemokine production and chemokine receptor expression in astrocytes. GLIA. 2003; 41:371-381.

58. Adams S, Teo C, McDonald KL, Zinger A, Bustamante S, Lim CK, Sundaram G, Braidy N, Brew BJ and Guillemin
GJ. Involvement of the kynurenine pathway in human glioma pathophysiology. PLoS One. 2014; 9:e112945.

59. Haslam G, Wyatt D and Kitos PA. Estimating the number of viable animal cells in multi-well cultures based on their lactate dehydrogenase activities. Cytotechnology. 2000; 32:63-75.

60. Norman JP, Perry SW, Kasischke KA, Volsky DJ and Gelbard HA. HIV-1 Trans Activator of Transcription Protein Elicits Mitochondrial Hyperpolarization and Respiratory Deficit, with Dysregulation of Complex IV and Nicotinamide Adenine Dinucleotide Homeostasis in Cortical Neurons. The Journal of Immunology. 2007; 178:869-876.

61. Schneider CA, Rasband WS and Eliceiri KW. NIH Image to ImageJ: 25 years of image analysis. Nature methods. 2012; 9:671-675.

62. King BA and Oh DH. Spatial control of reactive oxygen species formation in fibroblasts using two-photon excitation. Photochemistry and photobiology. 2004; 80:1-6. 